Supriadi. 2018. Manajemen Rekrutmen Guru Pendidikan Agama Islam di Sekolah Menengah Atas Islam Terpadu Nur Hidayah Surakarta Kecamatan Kartasura Kabupaten Sukoharjo

Jurnal Hadratul Madaniyah, Volume 5 Issue II, Desember 20I8, Page 60 - 72

P-ISSN: 2407-3865; e-ISSN: 2655-1993

\title{
MANAJEMEN REKRUTMEN GURU PENDIDIKAN AGAMA ISLAM DI SEKOLAH MENENGAH ATAS ISLAM TERPADU NUR HIDAYAH SURAKARTA KECAMATAN KARTASURA KABUPATEN SUKOHARJO
}

\author{
Supriadi, Universitas Muhammadiyah Palangkaraya \\ adianstercool@gmail.com
}

\begin{abstract}
ABSTRAK
Rekrutmen guru merupakan salah satu faktor pendukung keberhasilan suatu lembaga pendidikan.Rekrutmen yang dilakukan tidak hanya sekedar mengisi kekosongan pegawai atau sekedar mendapatkan guru, tetapi rekrutmen diharapkan bisa mendapatkan guru berdedikasi dibidangnya, sehingga dapat meningkatkan mutu.Pendidikan sekolah tersebut. Guru yang berkualitas bisa diperolch melalui proses rekrutmen yang baik. Dalam kondisi tersebut tim rekrutmen di SMAIT Nur Hidayah Surakarta. Kecarnatan Kartasura Kabupaten Sukoharjo berusaha untuk menghasilkan guru yang berkualitas bagus. Tujuan penelitian ini adalah untuk mendeskripsikan manajemen rekrutmen guru di SMAIT Nur Hidayah Surakarta Kecarnatan Kartasura Kabupaten Sukoharjo yang menghasilkan guru berkualitas bagus.

Penelitian ini menggunakan pendekatan deskriptif kualitatif.Pelaksanaan penelitian selama 4 bulan dimulai dari bulan Januari sampai April tahun 2014. Tempat penelitian di sekolah SMAIT Nur Hidayah Surakarta. Subjek penelitian adalah tim rekrutmen, diantaranya ketua rekrutmen, wakil ketua rekrutmen, dan penguji calon guru baru Sedangkan informan penelitian ini adalah ketua yayasan, kepala sekolah, guru, dan pegawai administrasi. Metode pengumpulan data dilakukan melalui observasi, wawancara, dan dokumentasi.Sedangkan teknik keabsahan data menggunakan triangulasi metode dan sumber. Teknik analisa data menggunakan model interaktif terdiri dari pengumpulan data, reduksi data, penyajian data dan verifikasi.
\end{abstract}

Kata kunci: Manajemen, rekrutmen, guru.

\section{ABSTRACT}

Recruitmentof teachersis one of thefactors supportingthe success ofan educational institution. Recruitmentiscarried outnot onlyto fillthe voidemployeeor toget ateacher, butrecruitmentis expected toget adedicatedteacherin the art, so as toimprove the quality ofschooleducation. Qualified teacherscan begainedthroughgood recruitmentprocess. Inthese conditionsthe recruitmentteaminSMAITNurHidayahSurakarta,Kartasura district, Sukoharjo regency triestoproduce of goodquality teachers. The purposeof this studyis to describe themanagement ofteacher recruitmentinSMAIT NurHidayah of Surakarta,Kartasura district, Sukoharjo regency thatproducesgood qualityteachers.

This research used descriptive qualitative approach. the implementation of this research was 4 months beginning from January until April 2014. Object of this research was SMAIT Nur Hidayah of Surakarta. Subject of this research was recruitment teams, including of recruitment chief, vice of recruitment chief, and candidate of new teacher's assessors. The informants of this research were chief of institution, Principal, teachers, and administration officers. Data collecting method applied observation, interview, and documentation, while, data validation 
Supriadi. 2018. Manajemen Rekrutmen Guru Pendidikan Agama Islam di Sekolah Menengah Atas Islam Terpadu Nur Hidayah Surakarta Kecamatan Kartasura Kabupaten Sukoharjo

Jurnal Hadratul Madaniyah, Volume 5 Issue II, Desember 2018, Page 60 - 72

P-ISSN: 2407-3865; e-ISSN: 2655-1993

techniques used triangulation method and sources. Technique of data analysis used interactive model consisting of data collecting, reduction, performing, and verification.

Key words: Management, implementation of recruitment, teacher.

\section{PENDAHULUAN}

\section{A. Latar Belakang Masalah}

Tinggi rendahnya sumber daya manusia sangat ditentukan oleh tenaga pendidikan (guru) yang ada pada negara tersebut. Karena tenaga pendidik dan kependidikan adalah seperangkat kegiatan dan proses yang dipergunakan untuk memperoleh sejumlah orang yang bermutu pada tempat dan waktu yang tepat sesuai dengan ketentuan hukum, sehingga orang dan sekolah dapat saling menyeleksi berdasarkan kepentingan terbaik masing-masing dalam jangka panjang maupun jangka pendek.

Salah satu permasalahan yang sering terjadi dibeberapa sekolah dalam melakukan rekrutmentenaga pendidik dan kependidikan yaitu masalah perencanaan rekrutmentenaga pendidik dan kependidikan yang kurang matang, sehingga sering kali terjadi diskualifikasi dan ketidakefektifan tujuan sekolah karena banyak pekerjaan-pekerjaan yang seharusnya dilakukan oleh beberapa orang harus dikerjakan sendirian.Hal tersebut terjadi karena kurangnya tenaga yang ahli dalam bidang-bidang pekerjaan tertentu, dan ketidak sesuaian penempatan personil terhadap tugas serta fungsinya.

Penelitian ini melihat dari kebanyakan sekolah dalam merekrut guru hanya melakukan dengan manajemen seadanya saja, sehingga seringkali terdapat kesalahan dalam perekrutan dilembaga pendidikan yang bersangkutan dengan apa yang diharapkanHal tersebut disebabkan olehketidak telitian dalam perekrutankarenabanyak lembaga sekolah yang tidak menggunakan pelaksanaan manajemen rekrutmenyang baik dalam melaksanakan perekrutan tenaga pendidik, sehingga guru yang direkrut tidak bisa untuk membawa sekolah menuju yang lebih baik seperti apa yang diharapkan oleh lembaga sekolah yang bersangkutan.

Namun berbeda halnya dengan Guru dan siswa yang ada diSMAIT Nur Hidayah, merupakan orang-orang yang memiliki kualitas diatas rata-rata. Pada umumnya seleksi guru hanya menghasilkan guru yang kualitas biasa, tapi berbeda dengan sekolah SMAIT 
Supriadi. 2018. Manajemen Rekrutmen Guru Pendidikan Agama Islam di Sekolah Menengah Atas Islam Terpadu Nur Hidayah Surakarta Kecamatan Kartasura Kabupaten Sukoharjo

Nur Hidayah yang melakukan seleksi guru dengan sangat bagus, hal ini terlihat dari banyaknya siswa yang mendapatkan prestasi, diantaranya sebagai juara I siswa teladan putri se Sukoharjo, begitu juga dengan lomba kepramukaan yang baru ini membawa 4 piala, Juara 3 hasta karya yakni membuat candi dari koran bekas, Juara 2 Ahmad Dahlan Night dengan menampilkan Tari Merak, Juara 3 Pionering dengan membuat tiang Merak, dan Juara 3 Korve $(5 \mathrm{H})$, serta banyak lagi prestasi yang diraih oleh SMAITNur Hidayah, semua itu tidak lepas dari peran seorang guru yang membimbing serta membina anak didiknya. Selain memiliki kualitas di atas rata-ratamereka juga ditempatkan sesuai dengan keahlian yang mereka miliki.

\section{B. Rumusan Masalah}

Berdasarkan uraian dari latar belakang masalah tersebut, maka dapat dirumuskan masalah sebagai berikut:

1. Bagaimana pelaksanaan rekrutmenguru pendidikan agama Islam di SMAIT Nur Hidayah?

2. Mengapa rekrutmenguru pedidikan agama Islam di SMAIT Nur Hidayah dapat menghasilkan guru yang memiliki kualitas tinggi?

\section{Kajian Teoritik}

1. Pengertian Rekrutmen

Rekrutmen guru didefinisikan sebuah usaha aktif dalam mencari calon potensial dengan cara mempengaruhi mereka agar bersedia mengisi posisi-posisi yang ada dalam sebuah lembaga pendidikan. Secara umum rekrutmenadalah aktivitas yang terencana dalam menarik sejumlah individu berkualitas yang dibutuhkan untuk mengemban tugas yang ada dalam suatu lembaga tersebut.Calon terbaik untuk mengisi sebuah posisi biasanya tidak datang sendiri untuk melamar pekerjaan.Sering kali pihak yang menyelenggarakan rekrutmenyang harus mencari, menentukan, dan meyakinkan calon paling berbakat untuk ikut bergabung. (James, 2008:126)

2. Pelaksanaan rekrutmen guru

Rekrutmen atau penerimaan tenaga kependidikan juga merupakan kegiatan untuk memenuhi kebutuhan tenaga kependidikan pada lembaga pendidikan, baik jumlah maupun kualitasnya.Untuk kegiatan tersebut diperlukan kegiatan penarikan. Menurut T. Hani Handoko (2001:69) 
Supriadi. 2018. Manajemen Rekrutmen Guru Pendidikan Agama Islam di Sekolah Menengah Atas Islam Terpadu Nur Hidayah Surakarta Kecamatan Kartasura Kabupaten Sukoharjo

mengemukakan bahwa "Penarikan (rekrutmen) adalah proses pencarian dan pemikatan para calon karyawan (pelamar) yang mampu untuk melamar sebagai karyawan. Sedangkan Anwar Prabu Mangkunegara

mengatakanrekrutmen adalah suatu proses atau tindakan yang dilakukan oleh perusahaan untuk mendapatkan tambahan pegawai yang melalui tahapan yang mencakup indentifikasi dan sumber-sumber penarikan pegawai, menentukan kebutuhan pegawai yang dibutuhkan perusahaan, proses seleksi, penempatan dan orientasi pegawai

3. Perencanaan rekrutmen

Perencanaan dilakukan demi menghindarkan terjadinya kesalahan dan kegagalan yang tidak diinginkan.Karena perencanaan rekrutmen ini dilakukan dengan analisis pekerjaan, agar tidak terjadi kesalahan dalam perekrutan.Menurut Malayu S.P Hasibuan (2007:28-29) mengatakan bahwa analisis pekerjaan adalah menganalisis dan mendesain pekerjaan apa saja yang harus dikerjakan, bagaimana mengerjakannya, dan mengapa pekerjaan itu harus dikerjakan, analisis pekerjaan bermanfaat untuk memberikan informasi tentang aktivitas pekerjaan, standar pekerjaan, persyaratan personalia, perilaku manusia, dan alat-alat yang akan dipergunakan.Dari analisa pekerjaan ini baik lembaga pendidikan, perusahaan maupun lembaga sosial lainnya dapat mempelajari dan mengumpulkan berbagai informasi yang berhubungan dengan berbagai operasi dan kewajiban suatu jabatan

4. Proses rekutmen guru

Penarikan tenaga kerja merupakan tindak lanjut dari perencanaan sumber daya manusia untuk mengisi kekosongan jabatan sesuai jumlah dan mutu tenaga kerja yang dibutuhkan. Penarikan tenaga kerja merupakan proses pencarian calon karyawan untuk diperkerjakan pada posisi yang ditentukan. Menurut Ibrahim Bafadal (2003:30-32) mengatakan proses rekrutmenguru bisa dilakukan melalui empat kegiatan yaitu: 1) persiapan rekrutmen guru, 2) 
Supriadi. 2018. Manajemen Rekrutmen Guru Pendidikan Agama Islam di Sekolah Menengah Atas Islam Terpadu Nur Hidayah Surakarta Kecamatan Kartasura Kabupaten Sukoharjo

Jurnal Hadratul Madaniyah, Volume 5 Issue II, Desember 2018, Page 60 - 72 P-ISSN: 2407-3865; e-ISSN: 2655-1993

penyebaran pengumuman

penerimaan guru baru, 3)

penerimaan lamaran guru baru,

4) proses seleksi pelamar.

Kegiatan pertama dalam proses rekrutmen guru baru, adalah melakukan persiapan rekrutmen guru baru. Persiapan rekrutmen guru baru harus matang sehingga melalui rekrutmen tersebut, sekolah bisa memperoleh guru yang baik. Kegiatan persiapan rekrutmen guru baru ini meliputi, 1) pembentukan panitia rekrutmen guru baru, 2) pengkajian berbagai undang-undang atau peraturan pemerintah, peraturan yayasan yang berkenaan dengan peraturan penerimaan guru, walaupun akhir-akhir ini telah diberlakukan otonomi daerah, (3) penetapan persyaratanpersyaratan untuk melamar menjadi guru baru,4) penetapan prosedur pendaftaran guru baru, 5) penetapan jadwal rekrutmen guru baru,6) penyiapan fasilitas yang diperlukan dalam proses rekrutmen guru baru, seperti media pengumuman penerimaan guru baru, format rekapitulasi pelamar, dan format rekapitulasi pelamar yang diterima, 7) penyiapan ruang atau tempat memasukan lamaran guru baru, 8) penyiapan bahan ujian seleksi, pedoman pemeriksaan hasil ujian dan tempat ujian.

Kegiatan yang kedua dalam proses rekrutmen guru baru, adalah melakukan penyebaran pengumuman penerimaan guru baru, begitu persiapan telah selesai dilakukan maka kegiatan berikutnya penyebaran pengumuman dengan melalui media yang ada seperti brosur, siaran radio, surat kabar dan sebagainya. Sudah tentu yang digunakan sebaiknya media yang dapat dengan mudah dibaca dan didengar oleh masyarakat.Pengumuman

penerimaan guru baru yang baik berisi tentang waktu, tempat, persyaratan, dan prosedur mengajukan lamaran.

Kegiatan yang ketiga dalam proses rekrutmen guru baru, adalah melakukan penerimaan lamaran guru baru, 
Supriadi. 2018. Manajemen Rekrutmen Guru Pendidikan Agama Islam di Sekolah Menengah Atas Islam Terpadu Nur Hidayah Surakarta Kecamatan Kartasura Kabupaten Sukoharjo

Jurnal Hadratul Madaniyah, Volume 5 Issue II, Desember 2018, Page 60 - 72 p-ISSN: 2407-3865; e-ISSN: 2655-1993

begitu pengumuman penerimaan

keterangan kelahiran yang

lamaran guru baru telah

disebarkan tentu masyarakat

mengetahui bahwa dalam jangka

waktu tertentu, sebagaimana

tercantum dalam pengumuman,

ada penerimaan guru baru

disekolah. Mengetahui ada

penerimaan guru baru itu, lalu

masyarakat yang berminat

memasukkan lamarannya.

Kegiatan yang harus

dilakukan panitia dalam

perekrutan guru dalam suatu

lembaga pendidikan, setidaknya

meliputi:1) melayani masyarakat

yang memasukkan lamaran

kerja, 2) mengecek semua

kelengkapan yang harus

disertakan bersama surat

lamaran, 3) mengecek semua

isian yang terdapat didalam surat

lamaran,seperti nama pelamar,

alamat pelamar, 4) merekap

semua pelamar dalam format

rekapitulasi pelamar.Untuk

melamar, seseorang diharuskan

mengajukan suratlamaran. Surat

lamaran tersebut harus

dilengkapi dengan berbagai surat

keterangan, seperti ijazah, surat

menunjukan umur pelamar, surat

keterangan warga Negara

Indonesia (WNI), surat

keterangan kesehatan dari

dokter, surat keterangan

kelakukan baik dari kepolisian.

Kegiatan keempat dalam

proses rekrutmen guru baru,

adalah melakukan proses seleksi

pelamar, setelah pendaftaran

atau pelamaran guru baru

ditutup, kegiatan berikutnya

adalah seleksi atau penyaringan

terhadap semua pelamar. Seleksi

merupakan suatu proses

pembuatan perkiraan mengenai

pelamar yang mempunyai

kemungkinan besar untuk

berhasil dalam pekerjaanya

setelah diangkat menjadi guru.

Ada lima teknik dalam hal ini

yaitu inventaris biografis,

wawancara, pemeriksaan badan,

teknik tes, dan penilaian oleh

pusat penilaian.Proses seleksi

mempunyai tujuan untuk

menyaring atau menyisihkan

orang-orang yang dianggap tidak

berbobot untuk memenuhi

persyaratan pekerjaan dan 
Supriadi. 2018. Manajemen Rekrutmen Guru Pendidikan Agama Islam di Sekolah Menengah Atas Islam Terpadu Nur Hidayah Surakarta Kecamatan Kartasura Kabupaten Sukoharjo

Jurnal Hadratul Madaniyah, Volume 5 Issue II, Desember 2018, Page 60 - 72 p-ISSN: 2407-3865; e-ISSN: 2655-1993

organisasi. Banyak tahapan dalam proses seleksi serta urutannya yang bervariasi.

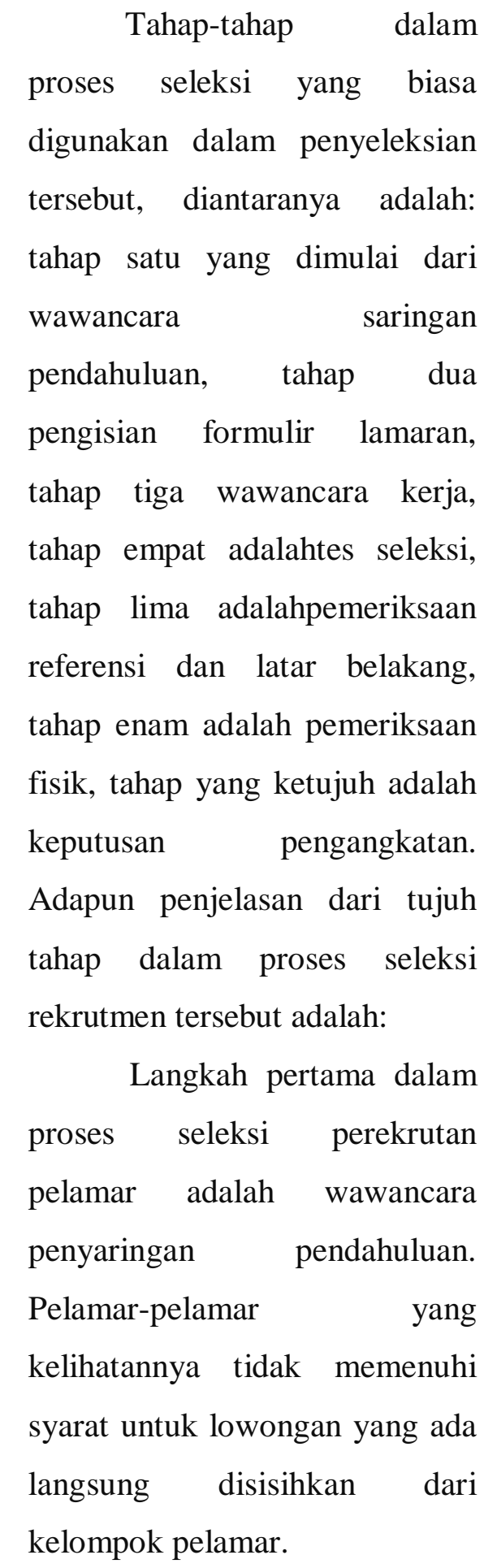

Tahap yang kedua dalam proses seleksi adalah pengisian formulir lamaran yaitu catatan formal lamaran pekerjaan seseorang. Pengisian formulir lamaran merupakan bagian dasar proses seleksi dihampir semua organisasi. Formulir lamaran berfungsi sebagai catatan aplikasi kepegawaian dan sebuah cara untuk menelusuri karakteristik pelamar manakala muncul lowongan kerja dimasa depan.

Tahapan yang ketiga
dalam proses seleksi adalah
wawancara kerja merupakan
percakapan formal dan
mendalam yang dilakukan untuk
mengevaluasi kemungkinan
penerimaan pelamar kerja.
Wawancara kerja dapat menilai pelamar atas sifat-sifat seperti penampilan pribadi, perangai, stabilitas emosi, kedewasaan, sikap, motivasi, dan minat (Henry Simamora, 2006:222229).

Tahap yang keempat dalam proses seleksi adalahtes seleksi yang menjadi bagian 
Supriadi. 2018. Manajemen Rekrutmen Guru Pendidikan Agama Islam di Sekolah Menengah Atas Islam Terpadu Nur Hidayah Surakarta Kecamatan Kartasura Kabupaten Sukoharjo

integral dalam proses seleksi.

Tes seleksi merupakan alat untuk menilai kemungkinan kecocokan antara pelamar kerja dengan persyaratan kerja.Tes seleksi merupakan ukuran yang obyektif dan terstandarisasi dari karakteristik manusia seperti kecerdasan, minat, kemampuan, dan kepribadian.

Tahap yang kelima
dalam proses seleksi adalah
pemeriksaan referensi dan latar
belakang, sebelum perusahaan
membuat keputusan hasil
seleksi, biasanya diadakan
terlebih dahulu penyelidikan
tentang latar belakang pelamar.
Penyelidikan latar belakang
disebut dengan pengecekan
referensi dan dapat mencakup
penelitian pekerjaan
sebelumnya, surat keterangan
pendidikan, aktivitas criminal,
dan karakter umum lainnya.
Tahap yang selanjutnya
adalah tahap keenam
yaitupemeriksaan

fisik.Pemeriksaan fisik diwajibkan untuk pekerjaanpekerjaan seperti pilot, kapten kapal, pengemudi truk, peneliti laboratorium dan banyak lagi yang lainya. Pemeriksaan fisik biasanya ditempatkan pada akhir proses seleksi.

Tahap yang terakhir atau yang ketujuh adalah keputusan pengangkatan.Keputusan seleksi biasanya diambil setelah wawancara akhir dengan pelamar dan setelah departemen sumber daya manusia memberikan rekomendasi (Henry Simamora, 2006:240247).

\section{Metodologi Penelitian}

Dalam penelitian ini penulis mengukan penelitian metode deskriptif kualitatif, metode deskriptif kualitatif ini dimaksudkan untuk menggambarkan apa adanya dengan jelas dan rincian mengenai Manajemen rekrutmenguru Pendididkan Agama Islam di SMAIT Nur HidayahKecamatan Kartasura Kabupaten Sukoharjo Jawa Tengah yang diungkapkan dan digunakan dalam hasil penelitian.

\section{E. Pembahasan dan Hasil Penelitian}

Deskripsi manajemen rekrutmen guru SMAIT Nur Hidayah Surakarta 
Supriadi. 2018. Manajemen Rekrutmen Guru Pendidikan Agama Islam di Sekolah Menengah Atas Islam Terpadu Nur Hidayah Surakarta Kecamatan Kartasura Kabupaten Sukoharjo

Kecamatan Kartasura Kabupaten

Sukoharjo.

Pelaksanaanrekrutmen guru yang telah dilaksanakan oleh SMAIT Nur Hidayah Surakarta merupakah sebuah inovasi dalam sebuah lembaga pendidikanuntuk perekrutan guru, badan pengurus yayasan Nur Hidayah memberikan pertimbangan dan persetujuan sesuai mekanisme rekrutmen, karena program rekrutmen dilaksanakan oleh yayasan Nur Hidayah yang diserahkan kepada panitia penerimaan guru atau tim yang ditugaskan.

Manajemen rekrutmen guru pendidikan agama Islamdi SMAIT Nur Hidayah Surakarta Kecamatan Kartasura Kabupaten Sukoharjo meliputi, perencanaan rekrutmen guru baru, sistem atau prosedur dalam pelaksanaan rekrutmen guru, strategi rekrutmen, seleksi guru dalam rekrutmen, dan hambatan-hambatan dalam perekrutan di SMAIT Nur Hidayah Surakarta.

Pelaksanaan perekrutan guru baru yang dilaksanakan SMAIT NH tidak semua calon pelamar mempunyai kualitas yang diharapkan oleh tim rekrutmen, sehingga perlunya evaluasi yang efektif dalam mengatasi kendala- kendala yang harus diselesaikan oleh tim rekrutmen. Dalam mengatasi kendalakendala tersebut, tim rekrutmen melakukan berbagai cara, sehingga kendala-kendala tersebut dapat diatasi dengan baik

\section{F. Kesimpulan}

Dari hasil observasi dan analisis peneliti tantang manajemen rekrutmen guru pendidikan agama Islam di SMAIT Nur Hidayah Surakarta, ada beberapa hal yang dapat disimpulkan adalah sebagai berikut:

1. Perencanaan perekrutan guru pendidikan agama Islam yang dilakukan oleh di SMAIT Nur Hidayah Surakarta sudah sangat baik yaitu dimulai dari analisi kekurangan guru yang dilaporkan oleh pihak sekolah serta melakukan penetapan persyaratan-persyaratan untuk pelamar calon guru baru yang akan direkrut, sehingga dapat menghasilkan calon guru yang berkualitas baik. Sedangkan untuk rekrutmen guru baru sepenuhnya dilakukan oleh tim atau panitia khusus yang ditunjuk oleh yayasan Nur Hidayah untuk mempermudah program kerja dalam proses rekrutmen guru baru. 
Supriadi. 2018. Manajemen Rekrutmen Guru Pendidikan Agama Islam di Sekolah Menengah Atas Islam Terpadu Nur Hidayah Surakarta Kecamatan Kartasura Kabupaten Sukoharjo

2. Sosialisasi pengumuman penerimaan guru baru yang dilakukan oleh tim rekrutmen sudah efektif yaitu dengan cara lewat pamflet, lewat sms, pengajuan permohonan kepada universitas-universitas terdekat untuk mendapatkan guru yang berkualitas baik.

3. Proses penyaringan rekrutmen calon guru baru di SMAIT Nur Hidayah Surakarta sudah dilaksanakan dengan baik dalam melakukan proses penyaringan, yaitu dimulai dari proses penyaringan administrasi, tes tertulis, tes wawancara, tes membaca Al-Qur'an serta hafalan mengenai Al-Qur'an, tes microteaching sampai kepada pengambilan keputusan yang dilakukan oleh tim rekrutmen, bahwa pelamar lulus untuk menjadi guru di SMAIT Nur Hidayah Surakarta.

4. Kebijakan yang diambil oleh tim rekrutmen dengan tidak melibatkan kepala sekolah dan guru yang ada di SMAIT Nur Hidayah secara khusus dalam perekrutan guru baru sudah sangat baik dan efektif, agar tugas guru yang ada di sekolah lebih fokus kepada kegiatan proses belajar mengajar saja dan tidak tercampur aduk dengan kegiatan lainya. Guru yang ada di SMAIT Nur Hidayah Surakarta hanya selaku penilai dalam peraktek tes microteaching sesuai dengan bidang yang mereka miliki, namun tidak semua guru dilibatkan dalam hal penilaian tes microteaching, hanya guru yang sama bidangnya saja yang diminta untuk menilai, sedangkan guru-guru yang tidak terlibat mereka lebih difokuskan kepada kegiatan belajar mengajar (KBM). Begitu juga dengan kepala sekolah yang tidak dilibatkan dalam perekrutan guru baru yang ada di SMAIT Nur Hidayah Surakarta.

5. Kendala yang dihadapi dalam pelaksanaan perekrutan guru baru di SMAIT Nur Hidayah Surakarta seringnya terdapat ketidaksesuaian antara guru yang dibutuhkan dengan pelamar calon guru baru, sehingga diperlukannya perekrutan yang berulang-ulang sampai mendapatkan calon guru yang benar-benar memenuhi standar yang diinginkan oleh pihak sekolah.

Adapun manajemen rekrutmen guru di SMAIT Nur Hidayah Surakarta dapat menghasilkan guru yang berkualitas baik, karena: 
Supriadi. 2018. Manajemen Rekrutmen Guru Pendidikan Agama Islam di Sekolah Menengah Atas Islam Terpadu Nur Hidayah Surakarta Kecamatan Kartasura Kabupaten Sukoharjo

1. Perencanaan rekrutmen guru baru yang dilakukan dengan cara menganalisis kebutuhan guru yang ada di SMAIT NH Surakarta.

2. Pengorganisasian yang dilakukan dengan cara pembentukan tim khusus dalam pelaksanaan rekrutmen guru baru.

3. Pelaksanaan rekrutmen yang meliputi kegiatan sosialisasi pengumuman penerimaan guru baru, seleksi administrasi, tes tertulis, tes wawancara, tes membaca serta hafalan Al-Qur'an, dan tes microteaching.

4. Pengawasan terhadap tim rekrutmen yang dilakukan oleh pihak yayasan dan kepala sekolah SMAIT NH dalam pelaksanaan rekrutmen guru baru.

5. Pengevaluasian yang dilakukan oleh tim rekrutmen dalam menyeleksi calon guru baru dengan menilai semua kegiatan-kegiatan dalam pelaksanaan rekrutmen guru baru di SMAIT NH Surakarta.

\section{G. Saran}

Setelah diperoleh temuan hasil penelitian, maka penelitian memberikan masukan sebagai berikut:
1. Kepada panitia atau tim rekrutmen yang bertugas, agar dalam melaksanakan proses rekrutmen harus selalu selektif dan tidak terpengaruh oleh tekanan-tekanan dari luar atau hal apapun.

2. Kepala sekolah, agar tidak melakukan intervensi terhadap pihak panitia dalam proses rekrutmen guru baru.

3. Kepada para guru SMAIT Nur Hidayah dengan diadakannya perekrutan guru yang selektif dan sistematis maka diharapkan lebih memotivasi para guru untuk meningkatkan kualitas dan kinerja guru dalam mengajar.

4. Kepada para peneliti lainnya diharapkan dapat melakukan penelitian serupa dengan objek yang berbeda agar kesimpulan yang diperoleh dalam penelitian ini dapat lebih mungkin digeneralisasi.

\section{DAFTAR PUSTAKA}

Admodiworo, Subagio.(2000). Manajemen Pendidikan di Indonesia. Jakarta: Ardya Jaya.

Arikunto, Suharsimi. (2008). Manajemen Pendidikan. Yogyakarta: Aditya Media, Cet. 1. 
Supriadi. 2018. Manajemen Rekrutmen Guru Pendidikan Agama Islam di Sekolah Menengah Atas Islam Terpadu Nur Hidayah Surakarta Kecamatan Kartasura Kabupaten Sukoharjo

Bafadal, Ibrahim. (2008). Peningkatan Profesionalisme Guru Sekolah Dasar.Jakarta: BumiAksara. Cet. 4.

Bangun Wilson. (2012). Manajemen Sumber Daya Manusia.Jakarta: PT Gelora Aksara Pratama.

Departemen Agama RI. (2005). Al-Qur'an dan Terjemahannya.Surabaya: CV. KaryaUtama.

Echols, Jhon M dan Hassan Shadily.(2005). Kamus Inggris-Indonesia. Jakarta: Gramedia.Cet. 26.

Fattah, Nanang. (2008). Landasan Manajemen Pendidikan, Bandung: Remaja Rosdakarya. Cet. 9.

Gomes, Faustino Cardoso. (2003). Manajemen Sumber Daya Manusia. Yogyakarta: C.V Andi offset.

Hamalik, Oemar. (2008). Manajemen Pengembangan Kurikulum. Bandung: Remaja Rosda Karya.

Handoko, T. Hani. (2001). Manajemen Personalia dan Sumber Daya Manusia, Yogyakarta: BPFE. Cet. 15.

Hasibuan, Malayu S. P. (2007). Manajemen Sumber Daya Manusia. Jakarta: Bumi Aksara. Cet. 10.

Hasibuan, Malayu S. P. (2007). Manajemen, Dasar, Pengertian dan Masalah, Jakarta: Bumi Aksara. Cet. 6.

Huberman Milles dan. (1999). Analisis Data Kualitatif, Jakarta: Universitas Indonesia Press.
Irwan Nasution dan Syafaruddin. (2005). Manajemen Pembelajaran. Quantum Teacing. Ciputat: PT Ciputat Prees.

James J. Jones dan Donal L. Walters. (2008). Human Resource Manajemen In Edication. Yogyakarta: Q-Media.

Umam Khaerul. (2012). Manajemen Organisasi. Bandung: Pusta Setia.

Moleong J. Lexy. (2004). Metode Penelitian Kualitatif, Bandung: CV. Remaja Rosdakarya.

Mangkunegara, A.A Anwar Prabu. (2004). Manajemen Sumber Daya Manusia Perusahaan.Bandung :Remaja Rosdakarya. Cet. 5.

Moleong J. Lexy. (2004). Metode Penelitian Kualitatif. Bandung: CV. Remaja Rosdakarya.

Mulyasa, E. (2003). Manajemen Berbasis Sekolah Strategi dan Implementasi.Bandung: Remaja Rosdakarya.

Mulyono.(2008). Manajemen Administrasi dan Organisasi Pendidikan.Yogyakarta: ArRuzz Media.

Peraturan Pemerintah RI No. 19 Tahun 2005.( 2006). Tentang Standar Nasional Pendidikan. Jakarta: Sinar Grafika.

Sagala, Syaiful. (2003). Kemampuan Profesional Guru dan Tenaga Kependidikan.Bandung: Alfabeta. 
Supriadi. 2018. Manajemen Rekrutmen Guru Pendidikan Agama Islam di Sekolah Menengah Atas Islam Terpadu Nur Hidayah Surakarta Kecamatan Kartasura Kabupaten Sukoharjo

Jurnal Hadratul Madaniyah, Volume 5 Issue II, Desember 2018, Page 60 - 72 P-ISSN: 2407-3865; e-ISSN: 2655-1993

Samsudin, Sadili. (2006). Manajemen Sumber Daya Manusia. Bandung: Pustakasetia. Cet. 1.

Sastrohadiwiryo, B. Siswanto. (2005). Manajemen Tenaga Kerja Indonesia Pendekatan Administrasi dan operasional.Jakarta: Bumi Aksara. Cet. 3.

Sutopo, H.B. 2002.Metodologi Penelitian Kualitatif. Surakarta. Universitas Sebelas Maret.

Simamora, Henry. (2006). Manajemen Sumber Daya Manusia edisi II. Yogyakarta: STIE YKPN. Cet. 2.

Soetjipto dan Raflis Kosasi.(2004). Profesi Keguruan. Jakarta: PT. Rineka Cipta.

Sofyan Syafri Harahap. (2007). Manajemen Kontemporer.Jakarta PT Raja Grafindo.

Subagyo Joko. (2004). Metode Penelitian. Jakarta: Rineka Cipta.

Suryabrata Sumadi. (2004).Metode Penelitian. Jakarta: PT.Raja Grafindo Persada.

Undang-undang RI. (2009). nomor 14 tahun 2005 \& Peraturan Pemerintah RI nomor 74 tahun 2008 tentang guru dandosen, Bandung: Citra Umbar.

Undang-Undang Sisdiknas 2003. (2006). Bandung: Fokusmedia.

Usman, Husaini. (2006). Manajemen Teori, Praktik, dan Riset Pendidikan. Jakarta: Bumi Aksara.
Usman, Moh. User. (2006). Menjadi Guru Profesional, Bandung: Remaja Rosdakarya. Cet. 9.

Yusuf Irianto. (2000). Manajemen Sumber Daya Manusia.Surabaya: Insan Cesdikia. 